\title{
Methodology of Innovative Economics
}

\author{
Kundakchyan R.M.
}

Mokichev S.D.

Kazan Federal University, Institute of Management, Economics and Finance, Kazan, 420008, Russia

\section{Doi:10.5901/mjss.2014.v5n24p327}

\section{Abstract}

The article explains the methodology of exploring innovation economy. New economic theory and the transition to the priority of innovative economic laws generate new theoretical problems and lead to the emergence of new areas of economic research methodology.

Keywords: Innovative economy, economic theory, methodology, method, hypothesis, modernization, transformation

\section{Introduction}

In the economic system, there is a radical change in the dependencies and regularities. Within the industrial system the economic processes lose their pattern of development inherent to them for centuries. Previously, the growing points of the economic system were formed on its local elements within the individual entities, and then extended spatially, forcing out the preceding economic organizations in the competitive struggle. The latter either ceased to exist or turned into marginalized forms of activity on the background of qualitatively and quantitatively dominant new economic models.

Similar processes can be observed today, but only in the context of transformation. In terms of the economic system transformation the focus is on the fact what is primary: either essential patterns and regularities of occurrence and operating of the innovative economic system, which are formed in a qualitatively different form, or the transformation of regularities in the industrial economic system.

Increase in the integrity of the new economic system and the transition to the priority of innovative economic laws generate new theoretical problems and lead to the emergence of new areas of economic research methodology.

The methodology of innovative economics as a new branch of scientific knowledge is based on the methods and models of the innovative economic processes research to identify regularities, trends, and implications. It is possible to suggest a new stage in the formation and development of the methodology of innovative economics, the reasons, the content, and the effects of innovation processes in the dynamics of the modern economic system. In our opinion, the novelty of the provisions put forward consists in understanding the methodology of innovative economics as a product of the whole previous progressive development of economics, which embodies the most important and time-proven achievements of all the scientific schools and trends. Secondly, the novelty consists in essential specification of the innovative economics subject, which includes, on the one hand, the problems of innovation and inherent modernization, and on the other hand, the theoretical and practical aspects of the property relations transformation. The third aspect is the development of the research methodology for the theory of the triple helix and determination of the innovation degree at the enterprises [6], [14].

The specifics of economic relations of the innovation economy consist in their complex nature. Hence the need to have a methodology that implements the heuristic function of the research subject is obvious. Any theoretical system of knowledge makes sense only if it not just describes and explains the required subject area, but is also a tool for finding new knowledge. The structural theory of innovation economy includes functions, principles and laws that reflect the essence of innovation, the original reasons, the value factors, and the logic of the innovative economics which fundamentally distinguish it from the industrial stage of development and, above all, a willingness to change and operate in a situation of constant update in production, structures, and institutions [5], [2].

From a functional point of view innovative economics is a set of interrelated provisions describing, explaining and predicting a variety of events of formation and development of the national innovation system. Therefore, the innovative economics performs synthetic, explanatory and predictive function. In addition, it performs a methodological function, as it serves as a basis for diverse methods, techniques and tools of research. "An Essay on the nature and significance of 
economic science" by Robbins [13] is often cited as an example of the approach, claiming the irrelevance of empirical tests to determine the truth or falsity of economic theory. As a supporter of radical apriorism Robbins considered the economic theory as a system of logical conclusions from a set of postulates, which, in turn, are generated by introspection and are not subject to empirical testing. [3]

The direct opposite of radical apriorism is an ultra empiricism, which adherents refuse to accept any postulate or premise that can not be directly verified. In other words, an ultraempirist offers to start with the facts, not the prerequisites [11], [12].

The leader of the British historical school W. Cunningham contrasted two ways of research: from events to their causes ("to identify economic phenomena and to seek conditions that caused them to life") and from cause to effect ("to highlight economic reasons and try to deduce necessary consequences from them "). [4] According to O. Ananyin, the historical school considered abstract theoretical analysis as secondary in relation to the empirical study of the historical experience of economic activity which was viewed as the main task of an economist [1].

Building models of innovative economics suggests that theoretical knowledge of innovation appears as a moment of discursive innovation practice, and basic assumptions and models, as certain components of dispositions and acts of thinking (observation, measurement, and search for rules of correspondence between empirical and theoretical languages, modeling, conceptualization, and construction of theoretical, ideal objects).

One can come to the empirical law of innovative economy development through industrial generalization of innovation process. The challenge is to turn the assembled system of innovative facts into the conceptual system to give them meaning and significance. Hypothesis and innovative economics, revealing empirical constructivism, are intended to explain the reality and must be confirmed: innovative facts - empirical laws of innovation economy - hypothesis confirmation.

Thus, the way to the innovative economics has its own characteristics. The center of gravity is shifted toward empiricism and realism. The following sequence in the development of the methodology for forming hypotheses and the innovative economics is formed: empirical realism - active realism - streamlined realism. This is the basic outline of the innovative economics methodology, but there are various modifications of modeling the future of modern economy. For example, cognitive human activity consists in the construction of an innovative economic model, which should be adequate to the world innovative laws. It is appropriate to use here the concept of "innovative empirical adequacy", which is understood as the coincidence of empirical manifestations of the theoretical model of the innovation economy and the most innovative economy.

Thus, the explanatory hypotheses of constructive empiricism are recognized as true when matching the innovation economy. They are locally true if they are adequate to the innovation economy. Means of achieving objectivity is the unity of subject and method of innovative economics. As emphasized by Kuhn, "paradigm formation and the appearance on its basis a more esoteric type of research is a sign of maturity of any scientific discipline" [10].

Today the state of innovative economics is characterized by a variety of theoretical approaches and conceptual provisions, the emergence and development of new areas, the search for new premises, and principles of universal constants, which would contribute to the establishment of a clear recognized paradigm of the innovation economy. There is a distinction between the "realism of the outside world» («World Realism»), which implies that the object of the innovative economics is an innovative system, as it is (and not as we would like to see it) and «Truth Realism», which implies that we judge the theory of innovation system comparing its results with real activity, and not only using the criteria of its internal consistency and satisfaction of initial axioms as a basis. But this naturally raises the question of what constitutes an "objective innovation system." It is obvious that this approach is closely related to positivism [11], [12]. If one includes in the concept of "real world" not only existing institutions and the state of science and technology in innovation system, but primarily the sum of notions of the subjects of innovative relations about their own innovation and innovations of others, about their own position on the modernization of their potential on a new basis, the concept of «World» becomes similar to the one that you can find in the strategic management - innovative system operates in both domestic and foreign environment.

"Truth Realism" as a criterion in relation to the innovation system allows to narrow the scope of analysis. Inside the criterion of "Truth Realism" one can distinguish between procedures which involve checking on the basis of a specific innovation process and procedures, which check the logic of the innovation process in the innovation system.

\section{Methodology}

Each national innovation system is specific. No basic theoretical model, even a "good" one and generally accepted in the scientific community can not be directly applied to economic analysis and forecasting. It requires the development of 
more detailed models that take into account a multitude of specific variables in a particular innovation system where this theoretical model will serve as a basis.

Neoclassical innovative economics does not adequately describe the features of a technologically advancing market economy and, at best, merely states that advancement, for example, by means of production functions.

Orthodoxy turns away from the real problems of technological progress, which often leads to a negative consequences and deep decline in production.

Evolutionary innovative economics sees economic development as an irreversible process of growing complexity, diversity and productivity of production due to recurrent change of technologies, products, organizations, and institutions.

To develop the innovative economics from the odds-formal logic it is necessary to point out a number of fundamental principles which one should adhere to.

The first principle is the recognition of the objective nature of the innovation process, which forms the subject of the economics. This means that all the innovative relations really exist outside of our consciousness.

The second principle is the analysis of innovative forms of relationships based on their classification and comparison of certain features in order to reveal their essence, or sustainable qualitative determination, which is characterized by a special, distinctive location and movement of the innovation economy in the economic system. Such analysis from the individual forms to their common core content is called the empirical method or the movement of knowledge from a single form to the abstract that is to substantiality of its content [16].

The third principle of formal-logical method of innovation economy cognition is the reverse ascent from the abstract (economic system) back to the specific (innovation system), but as a manifestation in it the cognized essence that is to essentially-specific. This method of cognition from the general to the specific is referred to as theoretical method. A characteristic feature of the modern science is intrascientific reflection which is a study of the innovation economy properties, supplemented by a new approach that is the use of forms and methods of scientific knowledge of innovation processes, new ways of raising questions relating to the methodology of the study of the innovation economy. It is proposed to understand under such a methodology the general view of the innovation economy, the object and the method of analysis, the purposes and methods of developing the innovative economics, the balance between theory and reality. The formulation "general view" captures the essence of the methodology pretty well, in which scientists and economists have repeatedly drawn attention to the significance of the individual energy in the economic development of innovative processes. Among them are K.Marx, V.Sombart, M.Weber, A. Bogdanov, J.Schumpeter. According to J. Maynard Keynes in particular "an appreciable part of our actions, because they are aimed at something positive, depend on spontaneous optimism rather than on rigorous calculations based on moral, hedonistic or economic motives. It is our innate desire for activity that drives the world" [7]. It is worth mentioning Weber's "spirit of capitalism", the "entrepreneurial natures" of Sombart and the role of the entrepreneur in the "creative destruction" of the economic equilibrium of Schumpeter. An innovative person and his tendency for the "creative destruction" have the world-historical significance and are found in any economic system [16]. A variety of manifestation forms for human innovation can include two aspects: information and energy. As information it means the data about innovation and innovative experience. As energy it suggests a mobilization force that transforms the information into a system of innovation priorities and values, ensuring a high level of productive innovative motivation or degree of innovation commitment of an innovative person.

The choice of methodology, as well as the choice of the investigated problem of the innovation economy, is, in some way, the art of competent identification of the innovation economy problem. But this is only the first part of the research problem. The second important issue is the right choice of the research methodology for the problems of innovation economy.

The criteria for selection of research methodology are as follows: the factor of scientific character; the role of human innovation; the factor of dynamics; the factor of target; the factor of creative destruction.

Methods of research:

- Empirical, including organizational, functional-structural and functional-cost innovation.

- Scientific - conceptual (socio-economic, diachronic, program-target).

- Pragmatic (technocratic, informational).

Methodology as a way of exploring the innovation economy is diverse. It can be classified as follows:

- scientific methodology and methodology of different types of knowledge depending on the area of knowledge of innovation economy, where the methodology is used;

- quantitative methodology and qualitative methodology depending on the type of innovative relations;

- inductive methodology, interpretive methodology, experimental methodology, modeling methodology, evolutionary methodology, depending on the type of method used;

- universal methodology, general scientific methodology and science specific methodology according to the 
levels.

According to E. Korotkov the content of the research methodology includes: the purpose and the object of research (current and future); approaches (systemic, aspective, conceptual, empirical, pragmatic, scientific); guidelines and limitations (rigid, predictable, soft, unpredictable); ways and means of research; research methods (specific, formally logical and valid) [9].

\section{Conclusion}

Hypothesis and innovative economics disclose the streamlined realism and are aimed at solving the problems of economy modernization. Hypothesis and innovative economics containing constructive rationalism have the most sophisticated methodological framework. This leads to the discovery of new ideas, new activities of enterprises and organizations that will reshape the economy and generate a whole new industry. The main criterion for their evaluation is the novelty and usefulness of economic modernization. Reliance on a given model designs the future that is based on the refinement of the existing reality.

Methodology and the style of innovation economy cognition are closely inter-related and represent the general principles of research for the study of innovation economy, ensure interdisciplinary synthesis, develop the outlines of the innovation economy problem and its method of verification, analyze the ideological standards of knowledge.

\section{References}

Ananyin O. Economy: Science and / or Art // Voprosy ekonomiki.-2007.-\#11.-pp.4-5

Bagautdinova, N.G., Galeeva, G.T., Kundakchyan, R.M. Development of the corporate management system in the modern context // World Applied Sciences Journal, 27(13), 2013, pp.43-47.

Blaug M. (1992) The Methodology of Economics, or How Economists Explain, Cambridge Surveys of Economic Literature, 316P.

Cunningham W.A. (1997) Plea For Pure Theory, The Economic Review, Routledge and Thames Press, Vol.2,7, P.33.

Gusakov M.A. The institutional environment for development of breakthrough technologies // Innovatsii.-2012.-\#6.-pp. 23-29

Etzkowitz, H., S. Fuchs, N. Gupta, C. Kemelgor and M. Ranga (2007), 'The Coming Gender Revolution in Science, In: E. J. Hackett, O. Amsterdamska, M. Lynch and J. Wajcman (eds) New Handbook of Science and Technology Studies (3rd edition), Cambridge: MIT Press.

Keynes J.M. (1936) The General Theory of Employment, Interest and Money, Palgrave Macmillan (2007 edit.), 472P.

Kundakchyan R., Grigoryeva N. Econometric Modelling Of Indicators Of Innovation Activity Level, American Journal of Applied Sciences 11 (9): 1578-1583, 2014.

Korotkov E.M. Investigating Management System.-M.: DEKA, 2003.-336p.

Kuhn T. (1962) The Structure of Scientific Revolutions, University of Chicago Press (2012 Edit.), 264P.

Mokichev S.V. Methodology of Economic Research.-Kazan: Kazan University, 2009.-244c.

Mokichev, S.D. The Influence of Cooperative Connections On Innovation activities of enterprises, World Applied Sciences Journal Volume 27, Issue 2, 2013, pp.212-215.

Robbis L. (1945) An Essay on the nature and significance of economic science, MACMILLAN AND CO., LIMITED ST. MARTIN'S STREET, LONDON

Safiullin L.N. Fatkhiev A.M. Grigorian K.A. The Triple Helix Model of Innovation / Safiullin L.N. Fatkhiev A.M. Grigorian K.A. // Mediterranean Journal of Social Sciences. Vol. 5, № 18 (2014).

Sallet J. Paisley E. Innovation Clusters Create Competitive Communities, Huff Post Social News. September 21, 2009 , p.3 